\title{
Influence of MOOC learners discussion forum social interactions on online reviews of MOOC
}

\author{
Bing $\mathbf{W u}{ }^{1}$ \\ Received: 17 November 2020 / Accepted: 9 December 2020/ Published online: 7 January 2021 \\ (C) The Author(s) 2021
}

\begin{abstract}
Although some studies have explored massive open online courses (MOOCs) discussion forums and MOOC online reviews separately, studies of both aspects are insufficient. Based on the theory of self-determination, this paper proposes research hypotheses that MOOC learning progress has a direct impact on MOOC online reviews and an indirect influence on MOOC online reviews through social interactions in discussion forums, as well. Coursera the largest MOOC platform, is selected as the empirical research object, and data from learners who participated in the MOOC discussion forum and provided MOOC online reviews from August 2016 to December 2019 are obtained from the most popular course, "Machine Learning". After processing, data from 4376 learners are obtained. Then, according to research hypotheses, multi regression models are constructed accordingly. The results show that the length of MOOC online review text is affected by the MOOC learning progress, the number of discussion forum posts, the number of follow, the online review sentiment and MOOC rating. This study highlights the main factors that affect MOOC online reviews. As a result, some suggestions are put forward for the construction of MOOC.
\end{abstract}

Keywords MOOC $\cdot$ Discussion forum $\cdot$ Social interactions $\cdot$ Online reviews $\cdot$ Selfdetermination

\section{Introduction}

Massive Open Online Courses (MOOCs) break through traditional offline teaching methods, broaden the learners' minds from the perspective of scope and scale, and break down the limitations of learning time and space. As an open online course platform, MOOCs allow anyone who is interested in participating in a course to have the opportunity to participate in learning at any time and in any place to achieve optimal

Bing Wu

ww_bing@163.com

1 School of Economics and Management, Tongji University, Shanghai, China 
education resources (Altalhi 2020). The three major MOOC platforms, Coursera, edX and Udacity, have triggered the boom of MOOC education since 2011 (Carrera and Ramirez-Hernandez 2018).

In the MOOC platform, learners can decide a particular MOOC learning progress as the percentage of mandatory learning, according to their own learning requirements (Chaker and Impedovo 2020). Moreover, they can actively participate in MOOC discussion forums. Additionally, they can evaluate the course by leaving a MOOC online review, which is useful for the improvement and optimization of MOOC teaching (Wu and $\mathrm{Li} 2020$ ).

When purchasing products or using services from an online website, consumers often look for other consumers' reviews (Ghasemaghaei et al. 2018). Similarly, learnergenerated information is helpful in MOOC. Longer reviews are likely to receive more attention, due to the fact that longer reviews often reduce search costs (Salehan and Kim 2016).

Therefore, MOOC discussion forums and MOOC online reviews are important ways for MOOC platforms to provide communication and feedback for learners. It is necessary to combine these two forms of communication and feedback to explore the impact of participation in MOOC discussion forums on MOOC online reviews, but currently, most of the literature only studies MOOC discussion forums or MOOC online reviews separately.

Based on a literature review, this paper proposes the research hypothesis of the effect of participating in MOOC discussions forums on MOOC online reviews from the perspective of MOOC learners and selects the most popular course, "Machine Learning" in Coursera, the largest MOOC platform in the world, as the empirical research object. Thus, the hypothesis is tested by empirical research. In theory, this study broadens the research horizon and content of MOOC. In practice, the length of MOOC online review text can be studied according to MOOC learners' participation in discussion forums, so effective advices for improving MOOC learner satisfaction can be provided for MOOC teachers to adjust their teaching techniques and for MOOC platform managers to improve the platform design, as well.

\section{Literature review}

\subsection{Self-determination theory}

On the basis of fully understanding personal needs and environmental information, self-determination theory emphasizes self-motivation in the motivation process, meaning that individuals should make free choices regarding their actions. According to the theory of self-determination, all individuals have three basic psychological needs, i.e., autonomy, relevance, and ability, regardless of gender, age, and cultural differences (Khan et al. 2018).

Autonomy refers to the need for freedom or the perceptual choice of individual behavior. Individuals can choose to participate or not participate in an activity, and they can decide what to do within that activity. Cognitive evaluation theory believes that intrinsic motivation is enhanced when a person is given the opportunity to choose, feel, or decide. Relevance refers to the need for individuals to be associated with others 
including family members, friends, teachers, classmates, etc., to create a sense of security.

Individuals need to have a sense of challenge, which enables them to master their own pursuits and engage in an activity efficiently. Learning ability is a key motivation factor for MOOC learners to participate in MOOC learning. MOOC discussion forums provide learners with the ability to communicate and interact. MOOC online reviews provide learners with an independent environment for leaving an online review. Therefore, the learning ability of MOOC learners provides a motivational basis for MOOC learners to participate in discussion forums and leave online reviews. MOOC learners with faster learning progress are more likely to participate in MOOC discussion forums, improve communication relevance, and advance the autonomy of MOOC online reviews.

\subsection{Social interaction in MOOC discussion forums}

Social interaction refers to social activities in which people use certain methods or tools to transmit information and exchange ideologies to achieve a certain goal. Social interaction in MOOC discussion forums refers to the idea that MOOC learners post and reply to course-related exchanges. In MOOC discussion forums, MOOC instructors can post a topic for discussion and communication between MOOC learners and MOOC learners can reply, ask questions, and interact with others.

A lack of social interaction is one of the reasons that online learners feel lonely, which has a negative impact on online learning (Moreno-Marcos et al. 2019). If online learners persist in participating in the course discussion forum, the functions of support and companionship in the course discussion forum will be enhanced (Aldowah et al. 2019). Social learning and peer learning are important factors in promoting online learner participation (Swinnerton et al. 2017). Only when MOOC learners have a certain sense of belonging in MOOC learning, will they participate more actively in MOOC learning.

Social interaction in MOOC discussion forums is an important way for MOOC learners to exchange and share information, and it is also a key factor that affects the quality of MOOC learning. Social interaction has a strong impact on individuals' psychological needs and thus affects learners' involvement (Wise and Cui 2018). Collaborative learning is valuable and positively influences learning adherence and learning attitudes (Khan et al. 2018). Social interaction is a very important part of MOOC learning input, and the greater the MOOC learning input, the longer the MOOC learner will persist in their education (Hmedna et al. 2019). The status and quality of social interactions in MOOC discussion forums are explored by empirical study (Almatrafi and Johri 2019). The interaction level in MOOC discussion forums is comprehensively analyzed by comparing discussion forum posts, MOOC categories, MOOC teaching modes, MOOC learning support, and MOOC evaluation methods (Deng et al. 2019). The learners who participate in MOOC discussion forums are divided into post publishers and post reviewers to construct an interaction network, and then, social network analysis is used to analyze the structure characteristics of the network (Yang et al. 2017). The participation and activity of learners in MOOC discussion forums are studied according to MOOC learners' behavior (Moore et al. 2019), including the continuous learning time, number of posts, number of replies, etc. 
Some studies have found that MOOC learners who participate in MOOC discussion forum posts have a relatively higher completion rate. Additionally, people who post weekly are less likely to drop out of Coursera (Sukaina 2016). Based on Coursera data provided by the University of Edinburgh in 2013 and 2014, learners who insisted on MOOC learning and obtained certificates are more likely to post frequently or browse posts (Woodgate et al. 2015). Although only 3\% of MOOC learners participated in discussion forums, $52 \%$ of people who obtained a certificate participated in a forum more frequently (Sanchez-Gordon and Lujan-Mora 2016).

\subsection{Summary of the review}

The MOOC platform provides a discussion forum for MOOC learners to communicate with and learn from others (Moore et al. 2019). Meanwhile, the MOOC platform provides MOOC learners with the MOOC online review function for course rating and evaluation. Similar to online shopping, MOOC online reviews help others choose courses (Ghasemaghaei et al. 2018). Therefore, it is necessary to combine the MOOC discussion forum with MOOC online reviews to explore the impact of MOOC discussion forum participation on MOOC online reviews. However, the current research is lacking in this regard. The self-determination theory can be used to understand the MOOC learning progress and social interaction in the MOOC discussion forum, thus stimulating motivation for MOOC online review autonomy.

\section{Research hypotheses and research model}

\subsection{Research hypotheses}

According to self-determination theory, this study takes MOOC learning progress as learning ability, social interaction in MOOC discussion forum as learning interactivity, and MOOC online reviews as reviewing autonomy, to study the roles of ability, relevance and autonomy for MOOC learners.

\subsubsection{Effects of MOOC learning progress as ability}

Swinnerton et al. (2017) studied the MOOC learning behavioral characteristics of learners who published MOOC online reviews and found that these learners have higher rates of course completion and more active learning (Swinnerton et al. 2017). Hew (2016) studied three courses with a higher rating and completion rate and found that MOOC learning progress has a strong influence on MOOC rating and MOOC online reviews (Hew 2016).

Through analysis of the characteristics and learning effects of MOOC learners, it is found that MOOC learners who have more social interactions in a discussion forum enjoy better learning effects (Carrera and Ramirez-Hernandez 2018). Therefore, learning progress is the key ability of MOOC learners to cognitively participate. Learning progress provides the motivational basis for MOOC learners to seek social interactions in discussion forums and for MOOC online review autonomy. Therefore, this study proposes the following hypotheses. 
H1a MOOC learning progress has a positive impact on the length of MOOC online review text

H2a MOOC learning progress has a positive impact on the number of browse

\subsubsection{Effects of MOOC learners' social interactions as relevance}

When MOOC learners connect through frequent social interactions in MOOC discussion forums, they tend to interact more with familiar people and thereby express more intense of emotions regarding MOOC participation. Additionally, autonomy motivates MOOC learners to participate in MOOC online reviews (Xiang et al. 2018; Dixit et al. 2019). Therefore, MOOC online review participation can be seen as an explicit manifestation of the autonomy needs of MOOC learners. Moreover, the social interaction network size, network density and posts in MOOC discussion forums have significant positive impacts on MOOC online reviews (Zhang and Zhang and Liu 2019). Therefore, this paper proposes the following hypotheses.

H1b The number of discussion forum posts has a positive impact on the length of MOOC online review text

H1c The number of browse has a positive impact on the length of MOOC online review text

H1d The number of follow has a positive impact on the length of MOOC online review text

The main channel for peer interaction in MOOCs is the discussion forum, where MOOC learners can post, browse, like and follow posts. Peer interactions can encourage knowledge sharing among MOOC learners, which is a major factor in attracting learners to continue using MOOCs (Yang et al. 2017). Moreover, the network structure characteristics of MOOC discussion forums were analyzed, and the factors that affect the social interactions of MOOC learners in discussion forums were studied (Moore et al. 2019). Therefore, this paper proposes the following hypotheses.

H2b The number of discussion forum posts has a positive impact on the number browse

H3a The number of browse has a positive impact on the number of follow

$\mathrm{H} 3 \mathrm{~b}$ The number of discussion forum posts has a positive impact on the number of follow

H3c The number of like has a positive impact on the number of follow H4a The number of browse has a positive impact on the number of like H4b The number of discussion forum posts has a positive impact on the number of like

\subsubsection{Effects of MOOC online review sentiment and rating as autonomy}

Consumers' online review sentiment and online review length are significantly correlated with online ratings (Ghasemaghaei et al. 2018; Ling et al. 2018; Zhang et al. 
2019). The length of online review text is negatively correlated with online ratings, while online review sentiment is positively correlated with online ratings. This is because when consumers are dissatisfied with the offered products and services, they tend to write long online reviews. Online reviews with positive sentiment have higher ratings than long online reviews. Therefore, this study proposes the following hypotheses.

H1e MOOC online rating has a negative impact on the length of MOOC online review text

H1f MOOC online review sentiment has a positive impact on the length of MOOC online review text

\subsection{Research model}

Based on the above hypotheses, a research model based on self-determination theory is constructed in Fig. 1. As shown in Fig. 1, MOOC learning progress has a direct impact on MOOC online reviews and an indirect influence on MOOC online reviews through social interactions in discussion forums, as well.

\section{Data acquisition and analysis}

\subsection{MOOC platform selection}

As one of the world's largest online learning platforms, Coursera was founded in 2012 by two computer science professors at Stanford University. Coursera is distinguished from other online platforms by its in-depth cooperation with higher education

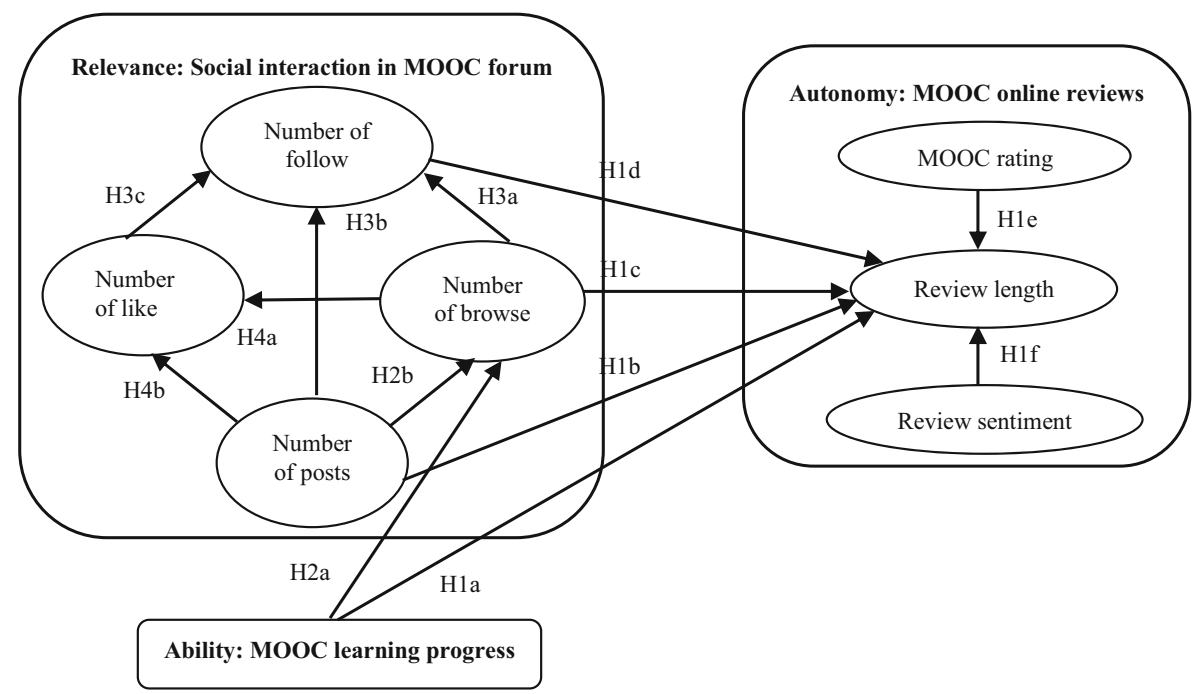

Fig. 1 MOOC Online Review Research Model 
institutions around the world, providing a wide range of related curriculum resources in popular majors, such as computer science, data science, information technology, mathematics, language learning, arts and humanities, and business. These courses with tests and assignments are taught by professors from the world's most prestigious institutions. Upon MOOC completion, MOOC learners will receive a completion certificate.

This paper selects Coursera as the empirical research object based on the following two reasons.

First, by 2019, Coursera announced that it has partnered with more than 150 universities and that 40 million people have studied through the Coursera platform. Learners can choose from 3200 courses, 310 special courses (a series of related courses to obtain a certificate), and 14 undergraduate and postgraduate degrees.

Second, Coursera provides MOOC discussion forums for learners to have discussions based on MOOC learning. Moreover, Coursera provides MOOC online review functions for MOOC learners to rate and review their courses online.

Therefore, Coursera provides ample research samples, and related research data, such as MOOC learning progress, social interaction behavior, online review and rating, can be obtained from Coursera. This study was designed to capture relevant research data from the "Machine Learning" course taught by Professor Wu Enda from Stanford University during the period from August 2016 to December 2019. "Machine Learning" is the most popular course on Coursera. There is a large number of MOOC learners. MOOC discussion forums and MOOC online reviews have accumulated a large amount of data for research. Finally, by deleting invalid data and removing blank data, data from 4376 learners who participated in both MOOC discussion forums and MOOC online reviews was acquired. Therefore, this article conducts research on 4376 anonymized learners.

\subsection{Variable description statistics}

The descriptive statistics of the variables is shown in Table 1.

The descriptive statistics of the MOOC online review length (mean $=158.71$, standard deviation $=206.817$ ) indicates that the MOOC online review length is usually long, but there is a large difference.

Table 1 Descriptive Statistics

\begin{tabular}{llllr}
\hline Variable & Min & Max & Average & Std. \\
\hline Online review text length(Cl) & 1 & 2593 & 158.71 & 206.817 \\
Learning progress (Pg) & 4 & 100 & 77.31 & 20.577 \\
Number of posts (Pn) & 1 & 212 & 5.62 & 9.261 \\
Number of browse (Pv) & 0 & 2765 & 87.41 & 167.694 \\
Number of follow (Pf) & 0 & 158 & 3.84 & 6.429 \\
Course online rating (Cr) & 1 & 5 & 4.9 & 0.368 \\
Online review sentiment(Cs) & -3 & 25 & 2.13 & 2.431 \\
Number of like (Pl) & 0 & 149 & 1.14 & 4.113 \\
\hline
\end{tabular}


The descriptive statistics of MOOC learning progress (mean $=77.31$, standard deviation $=20.577$ ) indicates that MOOC learners exhibit a higher degree of completion, but there are some differences.

The descriptive statistics of the total number of discussion forum posts (mean $=5.62$, standard deviation $=9.261)$, the number of browse $($ mean $=87.41$, standard deviation $=$ 167.694), the number of follow (mean $=3.84$, standard deviation $=6.429$ ) and the number of like $($ mean $=1.14$, standard deviation $=4.113)$ indicate little difference in social interaction in MOOC discussion forums.

The descriptive statistics of the course online rating (mean $=4.9$, standard deviation $=0.368)$ and online review sentiment $($ mean $=2.13$, standard deviation $=2.431)$ indicate that the $\mathrm{MOOC}$ has high online ratings with positive sentiment and that there is little difference.

\subsection{Multiple regression model}

To analyze whether the variables are independent, the Pearson correlation coefficient between each variable is calculated. The larger the absolute value of the Pearson correlation coefficient between two variables, the stronger the correlation; on the other hand, the closer the correlation coefficient value to 0 , the weaker the correlation. The coefficients between the variables in this study are all less than 0.6 , so the variables are independent of each other and multiple regression studies can be performed.

Based on the research hypotheses $\mathrm{H} 2 \mathrm{a}$ and $\mathrm{H} 2 \mathrm{~b}$ proposed above, with the number of browse $(\mathrm{Pv})$ as the dependent variable and the MOOC learning progress $(\mathrm{Pg})$ and the number of discussion forum posts by MOOC learners $(\mathrm{Pn})$ as independent variables, a multiple regression model (Model 1) is constructed as Eq.1.

$$
\mathrm{Pv}=\beta_{0}+\beta_{P g} P g+\beta_{P n} P n
$$

Based on the research hypotheses $\mathrm{H} 4 \mathrm{a}$ and $\mathrm{H} 4 \mathrm{~b}$ proposed above, with the number of like $(\mathrm{Pl})$ as the dependent variable and the number of discussion forum posts by MOOC learners $(\mathrm{Pn})$ and the number of browse $(\mathrm{Pv})$ as independent variables, a multiple regression model (Model 2) is constructed as Eq. 2.

$$
\mathrm{Pl}=\beta_{0}+\beta_{P n} P n+\beta_{P v} P v
$$

Based on the research hypotheses $\mathrm{H} 3 \mathrm{a}, \mathrm{H} 3 \mathrm{~b}$ and $\mathrm{H} 3 \mathrm{c}$ proposed above, with the number of follow (Pf) as the dependent variable and the number of browse (Pv), the number of discussion forum posts by MOOC learners ( $\mathrm{Pn})$ and the number of like (Pl) as independent variables, a multiple regression model (Model 3) is constructed as Eq3.

$$
\mathrm{Pf}=\beta_{0}+\beta_{P v} P v+\beta_{P n} P n+\beta_{P l} P l
$$

Based on the research hypotheses H1a, H1b, H1c, H1d, H1e and H1f proposed above, with the length of MOOC online review text $(\mathrm{Cl})$ as the dependent variable and MOOC learning progress $(\mathrm{Pg})$, the number of discussion forum posts by MOOC learner (Pn), the number of browse $(\mathrm{Pv})$, the number of follow $(\mathrm{Pf})$, MOOC online rating $(\mathrm{Cr})$ and online review sentiment $(\mathrm{Cs})$ as independent variables, a multiple regression model 
(Model 4) is constructed as Eq. 4.

$$
\mathrm{Cl}=\beta_{0}+\beta_{P g} P g+\beta_{P n} P n+\beta_{P v} P v+\beta_{P f} P f+\beta_{C r} C r+\beta_{C s} C s
$$

According to the above four regression models, multiple linear regression analysis was performed using SPSS22.0. All the variables in the four models have $0<\mathrm{VIF}<10$ and tolerance $>0.1$. The regression results are shown in Table 2 . Therefore, there is no multicollinearity problem for the variables of the multiple regression model constructed in this study (Salmeron et al. 2018).

Based on the regression results of Model 1 presented in Table 2, MOOC learning progress $(\mathrm{Pg})$ and the number of discussion forum posts by MOOC learners $(\mathrm{Pn})$ have significant positive effect on the number of browse $(\mathrm{Pv})\left(\beta_{R d}=0.962, p<0.001 ; \beta_{R l}=\right.$ $0.915, p<0.001)$. Therefore, hypotheses $\mathrm{H} 2 \mathrm{a}$ and $\mathrm{H} 2 \mathrm{~b}$ are supported.

Based on the regression results of Model 2 presented in Table 2, the number of browse $(\mathrm{Pv})$ has a significant negative influence on the number of like $(\mathrm{Pl})\left(\beta_{P v}=-\right.$ $0.003, p<0.001)$. Therefore, hypothesis H4a is not supported. Additionally, the number of discussion forum posts by MOOC learners $(\mathrm{Pn})$ has a significant positive effect on the number of like $(\mathrm{Pl})\left(\beta_{P n}=0.306, p<0.001\right)$. Therefore, hypothesis H4b is supported.

Based on the regression results of Model 3 presented in Table 2, the number of browse $(\mathrm{Pv})$, the number of discussion forum posts by MOOC learners $(\mathrm{Pn})$, and the number of like $(\mathrm{Pl})$ have significant positive effects on the number of follow $(\mathrm{Pf})\left(\beta_{P_{v}}=\right.$ $\left.0.014, p<0.001 ; \beta_{P n}=0.334, p<0.001 ; \beta_{P l}=0.096, p<0.001\right)$. Therefore, hypotheses $\mathrm{H} 3 \mathrm{a}, \mathrm{H} 3 \mathrm{~b}$ and $\mathrm{H} 3 \mathrm{c}$ are supported.

Based on the regression results of Model 4 presented in Table 2, MOOC learning progress $(\mathrm{Pg})$, the number of discussion forum posts by MOOC learners $(\mathrm{Pn})$, the number of follow (Pf), and MOOC online review sentiment (Cs) have significantly positive effects on the length of MOOC online review text $\left(\beta_{P g}=0.336, p<\right.$ $\left.0.001 ; \beta_{P n}=0.725, p<0.05 ; \beta_{P f}=1.468, p<0.001 ; \beta_{C s}=3.454, p<0.001\right)$. Therefore,

Table 2 Model Regression Result

\begin{tabular}{lllll}
\hline Model & $\begin{array}{l}\text { Model 1 } \\
\text { Number of browse }\end{array}$ & $\begin{array}{l}\text { Model 2 } \\
\text { Number of like }\end{array}$ & $\begin{array}{l}\text { Model 3 } \\
\text { Number of follow }\end{array}$ & $\begin{array}{l}\text { Model 4 } \\
\text { Review text length }\end{array}$ \\
\hline Constant & $-3.839(0.853)^{* * * *}$ & $\begin{array}{l}-0.299 \\
(0.058)^{* * * *}\end{array}$ & $\begin{array}{l}0.623 \\
(0.074)^{* * * *}\end{array}$ & $5.338(0.921)^{* * * *}$ \\
Pg & $0.962(0.105)^{* * *}$ & & & $0.336(0.108)^{* * *}$ \\
Pn & $0.915(0.234)^{* * *}$ & $0.306(0.006)^{* * *}$ & $0.334(0.010)^{* * * *}$ & $0.725(0.329)^{*}$ \\
Pv & & $-0.003(0.000)^{* * * *}$ & $0.014 、(0.000)^{* * *}$ & $-0.037(0.017)^{*}$ \\
Pf & & & & $1.468(0.528)^{* * * *}$ \\
Cr & & & $0.096(0.019)^{* * *}$ & $-5.693(0.859)^{* * * *}$ \\
Cs & & 0.632 & 0.730 & $3.454(0.287)^{* * *}$ \\
P1 & & 0.400 & 0.532 & 0.771 \\
R square & 0.519 & & & 0.595 \\
R adj square & 0.269 & & & \\
\hline
\end{tabular}

$* * * p<0.001, * * p<0.01, * p<0.05$ 
hypotheses $\mathrm{H} 1 \mathrm{a}, \mathrm{H} 1 \mathrm{~b}, \mathrm{H} 1 \mathrm{~d}$ and $\mathrm{H} 1 \mathrm{f}$ are supported. MOOC online ratings $(\mathrm{Cr})$ have a significantly negative effect on the length of MOOC online review text $(\mathrm{Cl})\left(\beta_{C r}=-\right.$ $5.693, p<0.001)$. Therefore, hypothesis H1e is supported. The number of browse (Pv) has a significantly negative effect on the length of $\mathrm{MOOC}$ online review text $(\mathrm{Cl})\left(\beta_{P v}=\right.$ $-0.037, p<0.05)$. Therefore, hypothesis H1c is not supported.

\subsection{Hypotheses test}

Summarizing the above results of hypotheses tests, as shown in Tables 3, 11 of the 13 research hypotheses are supported.

\section{Discussions}

When MOOC learning progress is faster, the number of browse is higher. Therefore, $\mathrm{H} 2 \mathrm{a}$ is supported, indicating that in the MOOC discussion forum, learners tend to browse posts from learners who learn faster.

The higher the number of discussion forum posts by MOOC learners, the greater the chances of being followed, browsed through, and liked, so H2b, H3b, and H4b are supported. Additionally, the higher the number of posts being browsed and being liked, the greater the chances of being followed, so $\mathrm{H} 3 \mathrm{a}$ and $\mathrm{H} 3 \mathrm{c}$ are supported. Unexpectedly, the number of browse has no significant positive effect on the number of like, so $\mathrm{H} 4 \mathrm{a}$ is not supported. This result shows that in MOOC discussion forums, posts that have been liked a lot are usually of higher quality and attract more MOOC learners to participate in discussion. As a result, the number of like depends on the quality of posts rather than on the number of browse.

Table 3 Summary of Hypotheses Test

Hypotheses

Supported

H1a MOOC learning progress has a positive impact on the length of MOOC online review text Yes

H1b The number of discussion forum posts has a positive impact on the length of MOOC online Yes review text

H1c The number of browse has a positive impact on the length of MOOC online review text No

H1d The number of follow has a positive impact on the length of MOOC online review text Yes

H1e MOOC online rating has a negative impact on the length of MOOC online review text Yes

H1f MOOC online review sentiment has a positive impact on the length of MOOC online review Yes text

H2a MOOC learning progress has a positive impact on the number of browse Yes

$\mathrm{H} 2 \mathrm{~b}$ The number of discussion forum posts has a positive impact on the number of browse Yes

H3a The number of browse has a positive impact on the number of follow Yes

$\mathrm{H} 3 \mathrm{~b}$ The number of discussion forum posts has a positive impact on the number of follow Yes

$\mathrm{H} 3 \mathrm{c}$ The number of like has a positive impact on the number of follow Yes

H4a The number of browse has a positive impact on the number of like No

H4b The number of discussion forum posts has a positive impact on the number of like Yes 
The learning progress of MOOC learners significantly positively affects the length of MOOC online review text, so H1a is supported. This is because MOOC learners with faster learning progress usually have a higher learning ability, which promotes a greater motivation for MOOC online review autonomy.

MOOC online rating significantly negatively affects the length of MOOC online review text, and the MOOC online review sentiment positively affects the length of MOOC online review text. Therefore, H1e and H1f are supported. This is because MOOC learners of "Machine Learning" are highly satisfied with the course (mean online rating is 4.9), so they tend to publish relatively short online reviews with positive sentiment.

The number of discussion forum posts by MOOC learners and the number of follow significantly positively affect the length of MOOC online review text, so H1b and H1d are supported. Inconsistent with the research hypothesis, the number of browse in the discussion forum has no significant positive influence on the length of MOOC online review text, so $\mathrm{H} 1 \mathrm{c}$ is not supported. This is because posting in MOOC discussion forum is the way that MOOC learners actively associate with others. Compared with being browsed through, being followed enables MOOC learners to have substantial interactions with others, thus engendering more autonomous motivation for MOOC learners to participate in online reviews

\section{Conclusions and implications}

Based on the theory of self-determination, this paper proposes research hypotheses and constructs a model to study the factors that influence MOOC online reviews. Coursera the largest MOOC platform, is selected as the empirical research object, and data from learners who participated in the MOOC discussion forum and provided MOOC online reviews from august 2016 to December 2019 are obtained from the most popular course, "machine learning"

The empirical results show the following. The MOOC learning progress, the number of discussion forum posts and the number of follow, have significantly positive effects on the length of MOOC online review text; however, the number of browse, has no positive effect on the length of MOOC online review text. The number of discussion forum posts indirectly affects the length of MOOC online review text by influencing the number of follow; meanwhile, the number of discussion forum posts indirectly affects the number of follow by influencing the number of like and the number of browse, respectively; unexpectedly, the number of browse has significant negative effect on the number of like. The MOOC online review sentiment has a significant positive effect on the length of MOOC online review text, while the MOOC rating has a negative effect on the length of MOOC online review text

Our significant finding is that the online review (as reviewing autonomy) of MOOC learners is affected by MOOC learning progress (as learning abilities), the number of follow and the number of posts (as social interaction) within discussion forums

\subsection{Theoretical implications}

First, based on the theory of self-determination, this study provides a theoretical basis that the online review autonomy of MOOC learners is affected by their learning abilities and social interaction within MOOC learner discussion forums. 
Second, most of the existing literature studies MOOC learner behavioral characteristics in MOOC discussion forums and MOOC online reviews separately. Research on the integration of MOOC discussion forums and MOOC online reviews is relatively lacking. Therefore, this study combines the social interactions in MOOC discussion forums and MOOC online reviews to explore the influencing factors of the length of MOOC online review text to study in depth the learning behavior of MOOC learners.

Third, there is little research on the influencing factors of the length of MOOC online review text. Therefore, taking the length of MOOC online review text as the dependent variable and MOOC learning progress, the number of discussion forum posts by MOOC learners, the number of browse, the number of follow and the number of like as independent variables, multiple regression analysis is used to research the influencing factors of the length of MOOC online review text.

\subsection{Practical implications}

\subsubsection{The impact of MOOC learning Progress}

MOOC learning progress directly affects the number of discussion forum posts and the length of MOOC online review text. However, the number of browse does not affect the length of MOOC online review text. Therefore, effective promotion of MOOC learning processes (for example, sorting and displaying MOOC learner posts according to learning progress in discussion forums) is a direct way to effectively improve MOOC online review autonomy.

\subsubsection{The impact of discussion forum posts and follow}

The number of forum discussion posts can significantly positively affect the length of MOOC online review text in the following four ways. First, the number of discussion forum posts directly affects the length of MOOC online review text. Second, the number of forum discussion posts indirectly affects the length of MOOC online review text by influencing the number of follow. Third, the number of discussion forum posts indirectly affects the length of MOOC online review text because the number of like influences the number of follow. Fourth, the number of forum discussion posts indirectly affects the length of MOOC online review text because the number of browse influences the number of follow. Furthermore, the number of follow directly affects the length of MOOC online review text. Therefore, encouraging MOOC learners to participate in the discussion forum and improve the social interaction quality in MOOC discussion forums (for example, setting MOOC discussion forum experience points, launching ranks or points leaderboards), is an effective way to improve MOOC learner autonomy in online reviews.

\subsubsection{The impact of MOOC rating and online review sentiment}

MOOC online review sentiment has a significant positive impact on MOOC online review length, while MOOC online rating has a significant negative impact on MOOC online review length, thus encouraging learners to write detailed comments on MOOC 
with positive emotional expression (for example, using bright and light tones in MOOC discussion forums to create a positive emotional atmosphere for MOOC learners to strengthen the willingness of other learners to write online reviews) not only contributes to improving MOOC online ratings but also encourages MOOC learners to publish a relatively long and useful online review, which provides a valuable reference for other MOOC learners when choosing courses

\section{Limitations and future research}

Due to the limitations of data acquisition, this paper selects the most popular course "Machine Learning" on the Coursera platform, and conducts empirical research on 4376 learners participating in both MOOC discussion forum interaction and course online reviews to validate the research hypotheses. Therefore, future study will examine other courses on Coursera to expand the scope of the empirical research. Consequently, the research model of this study needs to be further developed to add more research variables, such as subject type, as the control variable.

Acknowledgments (if applicable) This work was supported by Chinese National Social Science Fund "Thirteenth Five-Year Plan" education topic (BFA180064), and by the Shanghai Philosophy and Social Sciences Project (2016BGL002).

Open Access This article is licensed under a Creative Commons Attribution 4.0 International License, which permits use, sharing, adaptation, distribution and reproduction in any medium or format, as long as you give appropriate credit to the original author(s) and the source, provide a link to the Creative Commons licence, and indicate if changes were made. The images or other third party material in this article are included in the article's Creative Commons licence, unless indicated otherwise in a credit line to the material. If material is not included in the article's Creative Commons licence and your intended use is not permitted by statutory regulation or exceeds the permitted use, you will need to obtain permission directly from the copyright holder. To view a copy of this licence, visit http://creativecommons.org/licenses/by/4.0/.

\section{References}

Aldowah, H., Al-Samarraie, H., Alzahrani, A. I., \& Alalwan, N. (2019). Factors affecting student dropout in MOOCs: A cause and effect decision-making model. Journal of Computing in Higher Education, 32, 429-454. https://doi.org/10.1007/s12528-019-09241-y.

Almatrafi, O., \& Johri, A. (2019). Systematic review of discussion forums in massive open online courses (MOOCs). IEEE Transactions on Learning Technologies, 12(3), 413-428. https://doi.org/10.1109/TLT. 2018.2859304.

Altalhi, M. (2020). Toward a model for acceptance of MOOCs in higher education: The modified UTAUT model for Saudi Arabia. Education and Information Technologies. https://doi.org/10.1007/s10639-02010317-x.

Carrera, J., \& Ramirez-Hernandez, D. (2018). Innovative education in MOOC for sustainability: Learnings and motivations. Sustainability, 10(9), 2990. https://doi.org/10.3390/su10092990.

Chaker, R., \& Impedovo, M. A. (2020). The moderating effect of social capital on co-regulated learning for MOOC achievement. Education and Information Technologies. https://oi.org/10.1007/s10639-02010293-2.

Deng, R. Q., Benckendorff, P., \& Gannaway, D. (2019). Progress and new directions for teaching and learning in MOOCs. Computers \& Education, 129, 48-60. https://doi.org/10.1016/j.compedu.2018.10.019. 
Dixit, S., Badgaiyan, A. J., \& Khare, A. (2019). An integrated model for predicting consumer's intention to write online reviews. Journal of Retailing and Consumer Services, 46, 112-120. https://doi.org/10.1016/j. jretconser.2017.10.001.

Ghasemaghaei, M., Eslami, S.P., Deal, K., Hassanein,K. Reviews' length and sentiment as correlates of online reviews' ratings. Internet Research, vol. 28, no. 3, pp.544-563, 2018. https://doi.org/10.1108/IntR-122016-0394.

Hew, K. (2016). Promoting engagement in online courses: What strategies can we learn from three highly rated MOOCS? [J]. British Journal of Educational Technology, 47(2), 320-341. https://doi.org/10.1111/ bjet. 12235 .

Hmedna, B., El Mezouary, A., \& Baz, O. (2019). A predictive model for the identification of learning styles in MOOC environments. Cluster Computing-The Journal of Networks Software Tools and Applications, 23, 1303-1328. https://doi.org/10.1007/s10586-019-02992-4.

Khan, I. U., Hameed, Z., Yu, Y. G., Islam, T., Sheikh, Z., \& Khan, S. U. (2018). Predicting the acceptance of MOOCs in a developing country: Application of task-technology fit model, social motivation, and selfdetermination theory. Telematics and Informatics, 35(4), 964-978. https://doi.org/10.1016/j.tele.2017.09.009.

Ling, W., Gongliang, H., Tiehua, Z. (2018). Semantic Analysis of Learners' Emotional Tendencies on Online MOOC Education. Sustainability, 10(6). https://doi.org/10.3390/su10061921.

Moore, R. L., Oliver, K. M., \& Wang, C. (2019). Setting the pace: Examining cognitive processing in MOOC discussion forums with automatic text analysis. Interactive Learning Environments, 27(5-6), 655-669. https://doi.org/10.1080/10494820.2019.1610453.

Moreno-Marcos, P. M., Alario-Hoyos, C., Munoz-Merino, P. J., \& Kloos, C. D. (2019). Prediction in MOOCs: A review and future research directions. IEEE Transactions on Learning Technologies, 12(3), 384-401. https://doi.org/10.1109/TLT.2018.2856808.

Salehan, M., \& Kim, D. J. (2016). Predicting the performance of online consumer reviews: A sentiment mining approach to big data analytics. Decision Support Systems, 81, 30-40. https://doi.org/10.1016/j.dss. 2015.10.006.

Salmeron, R., Garcia, C. B., \& Garcia, J. (2018). Variance inflation factor and condition number in multiple linear regression. Journal of Statistical Computation and Simulation, 88(12), 2365-2384. https://doi.org/ 10.1080/00949655.2018.1463376.

Sanchez-Gordon, S., \& Lujan-Mora, S. (2016). How could MOOCs become accessible? The Case of edX and the Future of Inclusive Online Learning. Journal of Universal Computer Science, 22(1), 55-81.

Sukaina, W. (2016). Learning through engagement MOOCs as an emergent form of provision[J]. Distance Education, 37(2), 208-223. https://doi.org/10.1080/01587919.2016.1184400.

Swinnerton, B., Hotchkiss, S., \& Morris, N. P. (2017). Comments in MOOCs: Who is doing the talking and does it help? Journal of Computer Assisted Learning, 33(1), 51-64. https://doi.org/10.1111/jcal.12165.

Wise, A. F., \& Cui, Y. (2018). Learning communities in the crowd: Characteristics of content related interactions and social relationships in MOOC discussion forums. Computers \& Education, 122, 221242. https://doi.org/10.1016/j.compedu.2018.03.021.

Woodgate, A., Macleod, H., Scott, A. M., \& Haywood, J. (2015). Differences in online study behavior between sub-populations of MOOC learners. Education XX1, 18(2), 147-163. https://doi.org/10.5944/ educXX1.13461.

Wu, B., \& Li, P. (2020). Influence of MOOCs eWOM on the number of registrations and completions. IEEE Access, 8, 158826-158838. https://doi.org/10.1109/ACCESS.2020.3018132.

Xiang, L., Zheng, X. B., Zhang, K. Z. K., \& Lee, M. K. O. (2018). Understanding consumers' continuance intention to contribute online reviews. Industrial Management \& Data Systems, 118(1), 22-40. https:// doi.org/10.1108/IMDS-09-2016-0395.

Yang, T. Y., Brinton, C. G., Joe-Wong, C., \& Chiang, M. (2017). Behavior-based grade prediction for MOOCs via time series neural networks. IEEE Journal of Selected Topics in Signal Processing, 11(5), 716-728. https://doi.org/10.1109/JSTSP.2017.2700227.

Zhang, J. R., \& Liu, R. R. (2019). The more the better? Exploring the effects of reviewer social networks on online reviews. Journal of Marketing Management, 35, 1667-1688. https://doi.org/10.1080/0267257X. 2019.1666157.

Zhang, H., Huang, T., Lv, Z. H., Liu, S. Y., \& Yang, H. (2019). MOOCRC: A highly accurate resource recommendation model for use in MOOC environments. Mobile Networks \& Applications, 24(1), 34-36. https://oi.org/10.1007/s11036-018-1131-y.

Publisher's note Springer Nature remains neutral with regard to jurisdictional claims in published maps and institutional affiliations. 